Portland State University

PDXScholar

10-20-1994

\title{
The Effects of Phonological Processes on the Speech Intelligibility of Young Children
}

Susanne Shotola-Hardt

Portland State University

Follow this and additional works at: https://pdxscholar.library.pdx.edu/open_access_etds

Part of the Speech and Rhetorical Studies Commons

Let us know how access to this document benefits you.

\section{Recommended Citation}

Shotola-Hardt, Susanne, "The Effects of Phonological Processes on the Speech Intelligibility of Young Children" (1994). Dissertations and Theses. Paper 4780.

https://doi.org/10.15760/etd.6664

This Thesis is brought to you for free and open access. It has been accepted for inclusion in Dissertations and Theses by an authorized administrator of PDXScholar. Please contact us if we can make this document more accessible: pdxscholar@pdx.edu. 


\section{THESIS APPROVAL}

The abstract and thesis of Susanne Shotola-Hardt for the Master of Science in

Speech Communication: Speech and Hearing Sciences were presented

October 20, 1994, and accepted by the thesis committee and the department.

COMMITTEE APPROVALS:
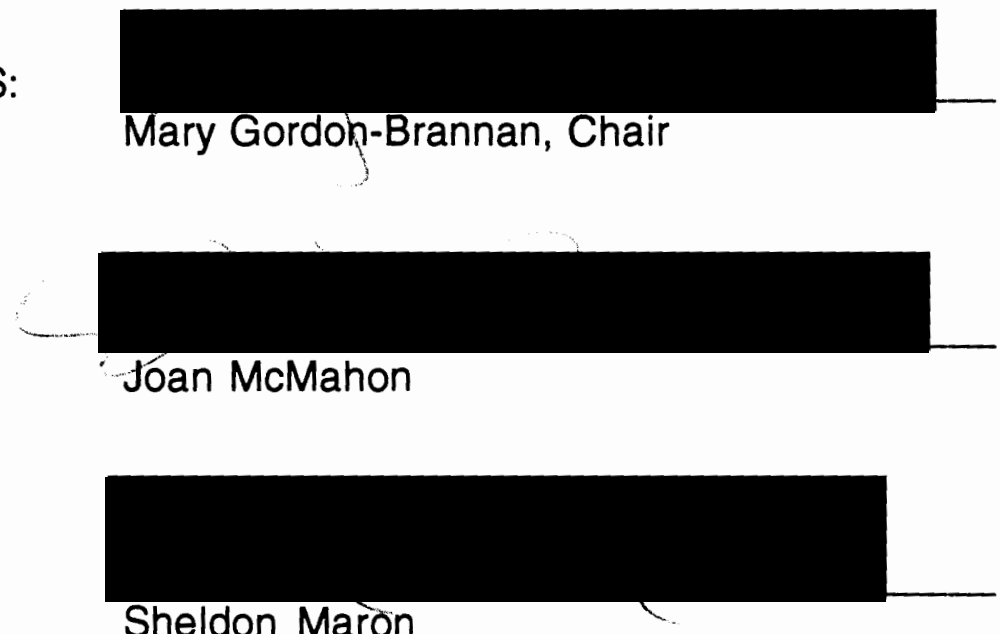

Sheldon Maron

Representative, Office of Graduate Studies

DEPARTMENT APPROVAL:

Stephen A! Kosokoff, Chair

Department of Speech Communication

ACCEPTED FOR PORTLAND STATE UNIVERSITY BY THE LIBRARY

by

on 5alecember $1 \mathrm{cp} 24$. 


\begin{abstract}
An abstract of the thesis of Susanne Shotola-Hardt for the Master of Science in Speech Communication: Speech and Hearing Sciences presented October 20, 1994.
\end{abstract}

Title: The Effects of Phonological Processes on the Speech Intelligibility of Young Children.

The purpose of this study was to explore the relationship between occurrence of 10 phonological processes, singly and in groups, with mean percentage of intelligibility of connected speech samples. Participants in the study included 4 adult listeners ( 3 females, one male) and 46 speakers aged 48 to 66 months ( 16 females, 30 males). Percentage of occurrence scores for phonological processes (independent variables) were obtained by the administration of The Assessment of Phonological Processes - Revised (Hodson, 1986). Percentage of intelligibility for 100-word connected speech samples (dependent variables) were obtained by orthographic transcription (words understood divided by 100 ).

The single processes showing the strongest negative correlation with intelligibility of connected speech included consonant sequence omission, glide class deficiency, syllable omission, and velar class deficiency, with reliability beyond the .001 level. The combination of consonant sequence omission, syllable omission, nasal class deficiency, and velar class deficiency accounted 
for $83 \%$ of the variance in the dependent variable. In this equation, consonant sequence omission alone accounted for $70 \%$ of the variance. Significance is beyond the .05 level for these measures. Results of the study lead to the recommendation that the following phonological processes are high priority targets for remediation: consonant sequence omission, syllable reduction and glide class deficiency, syllable reduction, and velar class deficiency. 


\title{
THE EFFECTS OF PHONOLOGICAL PROCESSES ON THE SPEECH INTELLIGIBILITY OF YOUNG CHILDREN
}

\author{
by \\ SUSANNE SHOTOLA-HARDT
}

\begin{abstract}
A thesis submitted in partial fulfillment of the requirements for the degree of

Master of Science in Speech Communication:

Speech and Hearing Sciences
\end{abstract}

Portland State University

1994 


\section{ACKNOWLEDGMENTS}

In finishing the requirements of the Master's degree in Speech and Hearing Sciences, I recall many people who have helped me during the past years. Foremost I thank my family members who have helped me achieve this goal: Christopher, our parents, siblings, and even nephews who have come into our family during this time. Your love and support has meant so much to me. Thanks especially to Dad for help with the statistical analysis.

I would like to take this opportunity to thank the faculty of the Speech and Hearing Science Program for the good work they do in producing successful speech-language pathologists and audiologists, and especially for their attention to individual students. I deeply appreciate the training I have received in this program. Thanks go to Joan McMahon, my academic advisor (happy retirement, Joan!), and to Mary Gordon-Brannan, my thesis advisor, for sharing data and her project with me. In addition, I would like to thank Ulrich Hardt and Michael Reardon for my assistantship working on the Oregon Literature Series. Thanks also to Shelly Maron for the recommendation letter to get into this program, and for serving on my committee. I will remember your great advice: "Make hay while the sun shines!"

In closing, I thank other students, friends whom I have come to know, and peers I have enjoyed working with--especially Dave and Sarah Andrews, Susan, Sharon, Kristi, Paul, Sharla, Jennifer, Jane, Debra, and Jodi. Best of luck with your careers! 


\section{TABLE OF CONTENTS}

PAGE

ACKNOWLEDGMENTS................................................................. ii

LIST OF TABLES ............................................................................ vi

\section{CHAPTER}

I INTRODUCTION AND STATEMENT OF PURPOSE... 1

Introduction ........................................................... 1

Statement of Purpose ......................................... 2

Terminology ....................................................... 2

॥ REVIEW OF THE LITERATURE........................................ 6

Phonological Processes ..................................... $\quad 7$

Instruments for Assessing Phonological Processes 9

Factors Affecting Intelligibility.............................. 11

Measures of Intelligibility...................................... 11

Summary............................................................ 15

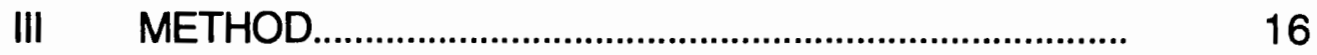

Participants.......................................................... 16

Procedures............................................................ 17

Data Analysis....................................................... 21

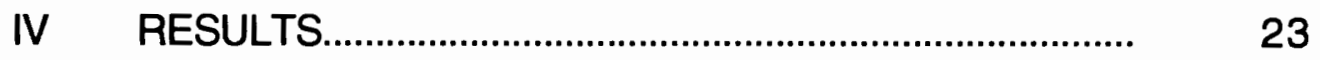

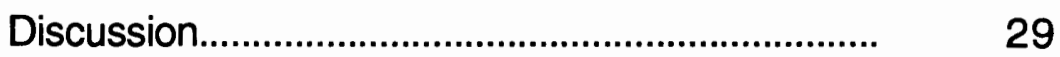


V SUMMARY AND IMPLICATIONS.............................. 32

Summary ................................................... 32

Implications.................................................. 34

Clinical................................................... 34

Research........................................... 35

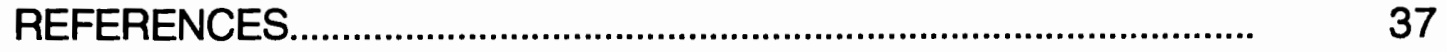

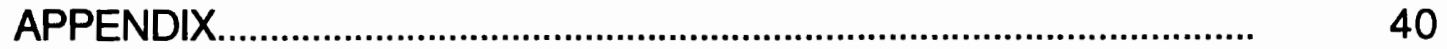

Speaker Characteristics 


\section{LIST OF TABLES}

TABLE

PAGE

1 Means, Standard Deviations, and Ranges

for 10 Phonological Processes

for 46 Subjects.

2 Correlation of Ten Phonological Processes

with Mean Intelligibility Rating of 100-Word

Continuous Speech Samples...........................................

3 Multiple Correlation of Percentage-of-Use of

10 Phonological Processes with Mean

Percentage-of-Intelligibility of 100 -Word

Connected Speech Samples ( $\mathrm{N}=46)$. 


\section{CHAPTER I}

\section{INTRODUCTION}

In assessing a client with phonological deficiencies, the measure of speech intelligibility is used as a rating of the client's communicative competence at the phonological level. Speech-language clinicians use both formal and informal methods of estimating the intelligibility of their clients' speech, including gross estimation of percentage of intelligibility or orthographic transcription, respectively. The percentage of intelligibility can be affected by variations in pause length, juncture, resonation, rhythm of speech, stress, intensity of voice, pitch, rate, and speech sound production (Weiss, 1982).

In the past, research has focused on the efficacy and objectivity of traditional methods of measuring speech intelligibility (Kent, Miolo, \& Bloedel, 1994; Shriberg \& Kwiatkowski, 1982), as well as the effects of the use of specific phonological processes on intelligibility of speech (Billman, 1986; Dunn \& Davis, 1983). However, the effects of combinations of phonological processes, as well as single processes, have yet to be fully explored. The combined effects of more than one phonological process on intelligibility need to be researched, since the effects of two or more phonological processes on a word can significantly reduce intelligibility (Yavas \& Lamprecht, 1988).

Speech sound errors that occur in patterns and operate systematically to simplify adult forms of words are known as phonologic processes (Hodson \& Paden, 1991; Weiss, Gordon, \& Lillywhite, 1987). After a link between specific combinations of phonological processes and their effect upon speech intelligibility is ascertained, then those processes with the greatest potential for improving intelligibility can be selected as priority intervention targets by 
speech-language clinicians. Since the primary objective for clients with articulation/phonological disorders is to improve intelligibility, ascertaining a hierarchy of effects of specific phonological processes singly and in combination would provide useful information to speech-language clinicians.

\section{Statement of Purpose}

The purpose of this study was to examine the relationship between the percentage of occurrence of 10 phonological deviations as measured by Hodson's (1986) Assessment of Phonological Processes - Revised (APP-R), singly and in combinations, and the degree of intelligibility of continuous speech of young children ages 4:0 to 5:6. Speech intelligibility was measured formally, derived from orthographic transcription.

The following research questions were posed for this study:

1. Are specific phonological processes correlated with increased or decreased intelligibility in connected speech of children with varying levels of phonological proficiency as derived from orthographic transcription?

2. Do specific phonological processes in combination correlate with increased or decreased intelligibility in connected speech of children with varying levels of phonological proficiency?

Terminology

The following terms are used for this investigation with definitions derived from Hodson and Paden (1991) and Weiss et al. (1987).

Assimilation/Consonant Harmony - A substitute consonant is produced which incorporates the place, manner, or voicing of production of another consonant in the target word which either precedes the target phoneme (progressive assimilation) or follows it (regressive assimilation). 
Assimilation of Manner of Production - The manner of production of the substituted consonant is the same as the target consonant (e.g., changing the stop manner of the target consonant to the fricative manner of another consonant in the target word, /s^f/for $/ t \wedge f)$.

Assimilation of Place of Production - The place of production of the substituted consonant is the same as another consonant in the target word (e.g., the bilabial place of production of the prevocalic consonant is substituted for the alveolar-dental place of production of the target consonant, $/ \mathrm{mæm} /$ for $/ \mathrm{m} æ n /$ ).

Assimilation of Voicing - The voicing characteristic of the target phoneme matches that of another phoneme in the word. This phonological process includes prevocalic voicing, when the voiced characteristic of the vowel is extended to the consonant (e.g., /gæp/ for /kæp/), and postvocalic devoicing, when the consonant following a vowel or final consonant of a word is produced without voice (e.g., /mætjas/ for /mæt $\int_{\partial z}$ ).

Backing - Place of production of the substitute consonant is located posterior to the place of production of the target consonant (e.g., /gagi/ for /dagi/).

Cluster Simplification/Reduction - Omission of at least one component of a consonant cluster or sequence (e.g., /b $\sum \mathrm{kfast} /$ for /br $\sum \mathrm{kfast}$ ).

Deaffrication - Substitution of a nonaffricate consonant for a target affricate consonant (e.g., /tif/ for $/ \mathrm{t}$ iff/).

Depalatalization - Substitution of a nonpalatal consonant for a target palatal consonant (e.g., /sap/ for /Jap/).

Diminution - Diminutive suffix /i/ is added to a noun (e.g., /dagi/ for /dag/). Doubling - Repetition or doubling of a syllable (e.g., /dædæ/ for /dæd/). 
Epenthesis - Insertion of a vowel (usually / /) or consonant into the target word (e.g., /bəlæk/ for /blæk)).

Final Consonant Deletion/Postvocalic Singleton Omission - Omission of a final singleton consonant of a word or syllable (e.g., /hæ/ for /hæt).

Final Devoicing - A postvocalic voiced consonant in word-final position is produced without voice (e.g., /b^s/for/b^z).

Fronting - Place of production of the substitute consonant is located anterior to the place of production of the target consonant (e.g., /tæn/ for /kæn/).

Gliding - A non-glide consonant is replaced by a glide consonant (e.g., $/ \mathrm{j} \sum \mathrm{wo} /$ for $/ \mathrm{j} \sum \mathrm{lo} /$ ). Gliding often occurs on the liquids $/ \mathrm{r} /$ and $/ / /$.

Initial Voicing/Prevocalic Voicing - A voiceless consonant preceding a vowel or in word-initial position is produced with voice (e.g., /gæn/ for /kæn/).

Liquid Deviation - Substitution, distortion, or omission of liquid consonants /r/, /V (e.g., /wak/ for/rak)).

Liquid Simplification - Substitution, distortion, or omission of liquid consonants /r/, /// (e.g., /wek/ for /lek).

Nasal Deviation - Substitution, distortion, or omission of nasal consonants (e.g., /baba/ for /mama/).

Palatal Fronting - A palatal consonant is replaced by a consonant produced at a more anterior place of production in the mouth (e.g., /sik/ for (tfik).

Prevocalic Singleton Omission - Deletion of a single consonant preceding a vowel (e.g., /æk/ for /bæk/).

Post-vocalic Singleton Omission/Final Consonant Deletion - Deletion of a single consonant following a vowel (e.g., /blæ/ for /blæk/). 
Reduplication - Repetition of one syllable replaces a target syllable (e.g., /baba/ for /badl/).

Stopping - A target liquid, nasal, glide, or fricative consonant is replaced by a stop consonant (e.g., /fIt/ for /fIJ/).

Stridency Deletion - Omission or substitution of strident consonants $/ s, 3, f$, $\left.v, \int, z, t\right], d_{z} /(e . g ., / k æ /$ for $/ k æ t / /$ ).

Syllable Assimilation/Syllable Harmony/Reduplication - Repetition of one syllable replaces a target syllable (e.g., /wawa/ for /wat $\left.\gamma^{\prime}\right)$ ).

Syllable Reduction - Omission of an unstressed syllable (e.g., $/ \Sigma$ lfənt for

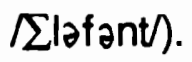

Velar Deviation - Omission of velar consonants $(/ k, g, \eta /)$ (e.g., /ar/ for /kar/), or substitution of non-velar consonants in place of a velar consonant (e.g., /tar/ for / kar//).

Velar Fronting - Substition of a velar consonant by a consonant produced anteriorly in the mouth (e.g., /tæt/ for /kæt).

Vocalization/Vowelization - Substitution of a vowel for a syllabic or postvocalic liquid consonant (e.g., /bado/ for /badl/).

Weak Syllable Deletion/Omission - Omission of an unstressed syllable (e.g., / $\sum$ lfant/ for $/ \Sigma$ lfant)). 


\section{CHAPTER II}

\section{REVIEW OF THE LITERATURE}

As children begin to acquire the fine motor movements required to produce recognizable phonemes in their native language, they are confronted with a vast number of sounds that are beyond their capabilities to produce. In order to communicate with the people in their environment, they must stretch their limited phonemic repertoire to represent those sounds that are beyond their production capabilities.During this phase of speech and language development, systematic rules govern the individual's method of simplifying the phonetic structure of a word in order to produce it. Rules that change the phonetic characteristics of the target word are known as phonological processes (Hodson \& Paden, 1991; Ingram, 1976; Weiner, 1979; Weiss et al., 1987). According to Ingram (1976), phonological processes are "organizational principles that [children] use to systematize" (p. 52) their perception of adult language forms. These processes operate over classes of sounds rather than individual sounds; the processes govern which phonemes are produced to approximate the adult forms, and they operate systematically depending upon the phonetic structure of the target word. The specific processes used are affected by phonetic context. Phonological processes can be identified in the speech of normal and disordered language learners (Churchill, Hodson, Jones, \& Novak, 1988; Grunwell, 1983; Hodson, 1982; Hodson \& Paden, 1991; Ingram, 1976; Oller, 1973; Stampe, 1969; Stoel-Gammon \& Dunn, 1985; Weiss et al., 1987). 
Phonological Processes

Phonological processes are categorized according to the differences in phonetic structure of the produced word compared to the phonemes present in the target word (Dyson \& Paden, 1983; Hodson, 1986; Ingram, 1976; Preisser, Hodson, \& Paden, 1988). Processes of omission are described in terms of the phonetic context in which the error occurs. For example, when a speaker fails to produce a word-initial phoneme consisting of a single consonant (e.g., /æt/ for /kæt), the process is classified as a prevocalic singleton omission (Hodson, 1986). Similarly, when a speaker fails to produce a word-final phoneme consisting of a single consonant (e.g., $/ \mathrm{kæ} /$ for $/ \mathrm{kæt} /$ ), the error is classified as a postvocalic singleton omission (Hodson, 1986).

While processes of omission are classified according to the phonetic context in which the omission occurs, processes of substitution are classified according to precise changes which occur in manner, place, and voicing of target word consonants (Hodson, 1986). For example, when a speaker substitutes one sound for another for an initial phoneme (e.g., /tæt/ for /kæt/), the substitution consists of a change in place of production from a velar position in the back of the mouth to a lingual-alveolar position in the front of the mouth. Since the manner (plosive) and voicing (unvoiced) of the phoneme remain unchanged, the process involved in this case is described as fronting. On another level, this substitution is an example of assimilation of place, since the place of production of the word-final consonant is duplicated.

The use of phonological processes follows a normal progression during the preschool years, with individual differences and exceptions (Dyson \& Paden, 1983; Ingram, 1976; Preisser et al., 1988; Weiss et al., 1987). A general progression of normal use of phonological processes by preschool children has 
been established. According to Stoel-Gammon and Dunn (1985), phonological processes used within normal age limits until age 3:0 include weak/unstressed syllable deletion, final consonant deletion, doubling, diminutization, velar fronting, consonant assimilation, reduplication, and prevocalic voicing. Phonological processes used within normal age limits beyond age 3:0 include cluster reduction, epenthesis, gliding, vocalization, stopping, and depalatalization. According to Grunwell (1983), weak syllable omission is used from age 2 until 3:6, and sometimes lasts until 4:0. Similarly, final consonant deletion, or postvocalic singleton omission, is used from age 2:0 until 2:6 or 3:0. Consonant cluster reduction is used from $2: 0$ until 3:8 or 3:9. Reduplication of syllables is a common process used early in speech development, especially in the first 50 words, and lasts until approximately age 2:6.

In a study of 60 normally developing children aged 1:6 to $2: 5$, Preisser et al. (1988) found cluster reduction and gliding of liquid consonants to be the most frequently used phonological processes among the subjects. In addition, these researchers found age 2:2 to be a significant point of development at which young children no longer use cluster reduction consistently; rather, they produce consonant sequences. Other processes used frequently by the youngest subjects (aged 1:6 to 1:9), but significantly less often by the older group (2:2 to 2:5), include: omission of postvocalic obstruents, omission of weak syllables, omission of prevocalic obstruents, stridency deletion, velar deviation, and nasal/glide deviation.

In a similar study, Dyson and Paden (1983) measured percentage-ofoccurrence for five phonological processes in 2-year-olds. Subjects were assessed every 3 weeks for 7 months to track their course of phonological development. Phonological processes measured in the study occurred in the 
following order of frequency: gliding, cluster reduction, fronting, stopping, and final consonant deletion. The subjects' use of gliding decreased to the least extent of the five processes, from $54 \%$ at first testing to $48 \%$. Cluster reduction decreased from $50 \%$ to $30 \%$. Fronting and stopping decreased from $16 \%$ to $10 \%$ and from $14 \%$ to $9 \%$, respectively. Final consonant deletion decreased to the greatest extent over the 7-month period, falling in use from $11 \%$ to $4 \%$ in normal speakers.

While phonological processes characterize normal speech development, their use has been documented in speakers with disordered speech also (Hodson \& Paden, 1981; Weiner, 1979; Weiss et al., 1987; Yavas \& Lamprecht, 1988). Hodson and Paden (1981) compared the phonological processes used by 60 normally developing English-speaking 4- and 5-year-old children with those processes used by 60 English-speaking 3- to 8-year-olds with phonological disorders. A comparison of the number of subjects using each process revealed that 60 unintelligible subjects used various combinations of processes including cluster reduction, stridency deletion, stopping, and liquid deviation. In contrast, 60 intelligible 4-year-olds used a single process, devoicing of final consonants. In later studies, Hodson (1982; Hodson \& Paden, 1983) found that speakers using substitution processes are more intelligible than speakers using sequential processes such as cluster reduction.

In a similar study, Yavas and Lamprecht (1988) analyzed phonological processes used by four 7- to 9-year-old Portuguese-speaking subjects with phonological disorders. Phonological processes that contributed to reduced intelligibility of these subjects included stopping and cluster reduction. Instruments for Assessing Phonological Processes A number of tests have been designed that measure children's use of 
phonological processes, including the Bankson-Bernthal Test of Phonology (BBTP) (Bankson \& Bernthal, 1990), the Khan-Lewis Phonological Analysis (KLPA) (Khan \& Lewis, 1986), and the Analysis of Phonological Processes Revised (APP-R) (Hodson, 1986).

The BBTP (Bankson \& Bernthal, 1990) measures use of the following 10 processes: assimilation, fronting, final consonant deletion, weak syllable deletion, stopping, gliding, cluster simplification, depalatalization, deaffrication, and vocalization of a syllabic or postvocalic liquid consonant. Administration of the test consists of presentation of 80 pictures. The child names the picture, and the clinician phonetically transcribes the child's productions. After all items have been elicited, the clinician analyzes the child's productions. The BBTP yields a raw/composite score, a standard score, and percentile rank for each of the following categories: word inventory, phonological process inventory, and consonant inventory, including specifying which consonants are consistently in error in word-initial and word-final positions.

The KLPA (Khan \& Lewis, 1986) is designed for use with the GoldmanFristoe Test of Articulation (Goldman \& Fristoe, 1986). The KLPA measures use of the following 10 phonological processes: deletion of final consonants, initial voicing, syllable reduction, palatal fronting, deaffrication, velar fronting, consonant harmony, stridency deletion, stopping of fricatives and affricates, cluster simplification, final devoicing, and liquid simplification. Administration of the test consists of presentation of 35 pictures to elicit 44 responses. The KLPA yields the following scores: developmental phonological process rating (for each process), speech simplification rating, composite score, percentile rank, and age equivalent.

Hodson's (1986) Assessment of Phonological Processes - Revised 
(APP-R) measures the use of 10 phonological processes based on a naming task of 50 items. Phonological processes measured by the APP-R and analyzed by the Computer Analysis of Phonological Deviations (CAPD) (Hodson, 1992) consist of two main categories, omissions and substitutions. Errors of omission include: syllable omission, prevocalic singleton omission, postvocalic singleton omission, and consonant sequence reduction. By analyzing the substitutions and omissions, class deficiencies are identified in the speaker's phonological system. Class deficiencies identified by the CAPD include stridents, velars, liquid $/ /$, liquid $/ r /$, nasals, and glides. In addition to the percentage-of-occurrence scores for each process listed above, the CAPD yields a phonological deviancy score, from which a severity rating is derived.

Factors Affecting Intelligibility

While the use of phonological processes significantly affects speech intelligibility, other elements also play a role in enhancing or diminishing intelligibility. According to Weiss (1982), factors that influence intelligibility include: adventitious sounds, articulation, communicative disfluency, inflection, juncture, mean length of utterance, morphology, morphophonemics, pauses, physical posture, pitch, pronunciation, rate, redundancy, resonation, rhythm, semantics, stress, syntax, voice quality, intensity, and pragmatics. The extent to which intelligibility is affected by these and other factors has been measured using several different techniques.

\section{Measures of Intelligibility}

Various techniques have been used by speech-language pathologists to determine the degree of intelligibility of a speaker, including informal and formal estimates. Informal subjective measures include a simple gross estimation of the percentage-of-words understood in a connected speech sample (Gordon- 
Brannan, 1993) and rating scales, including equal-appearing interval rating scales and direct magnitude scaling (Schiavetti, Metz, \& Sitler, 1981). Formal measures include multiple-choice format, performance on an articulation test (Fudala \& Reynolds, 1986), transcription (Weiss, 1982; Yorkston \& Beukelman, 1978), and sentence completion (Yorkston \& Beukeiman, 1978).

Subjective Estimates of Intelligibility

To determine subjectively the intelligibility of a speaker using an equalappearing interval scale, the listener is presented with a 3-, 5-, 7-, or 9-point scale. The scale is visually represented with equal space between the numbers. Depending on the scale, descriptors are provided for all points, for the far and medial points of the scale (e.g., "essentially unintelligible" corresponding to an end point, "sometimes intelligible" corresponding to a point in the center, and "essentially intelligible" corresponding to the other end point), or for the end points (e.g., "essentially intelligible/unintelligible"). Immediately after listening to the speech sample, the listener rates the speaker using this scale (Gordon-Brannan, 1993; Schiavetti et al., 1981).

Using the direct magnitude scaling technique, a standard stimulus is used in order to generate ratings of intelligibility relative to that standard (Schiavetti et al., 1981). The first speech sample is assigned a random number value. This number becomes the standard against which following samples are judged. Each following sample is assigned a number value relative to the first.

To make an informal subjective estimate of the degree of intelligibility of a continuous speech sample, listeners simply provide the number between $0 \%$ and $100 \%$ that they judge most closely corresponds with the amount of speech they are able to understand. Although this method is expedient and uncomplicated, it has been labeled as one of the least objective procedures 
currently practiced by speech-language clinicians (Monsen, 1981; Shriberg \& Kwiatkowski, 1982). In fact, a comparison of listener estimates of percentage of intelligibility of elicited pairs of words with an objective measure of the same pairs of words has indicated that psychometric perceptions of intelligibility range only from $60-100 \%$ of words understood, rather than from $0-100 \%$.

Monsen (1981) devised a rating scale with four points (highly intelligible, primarily intelligible, primarily unintelligible, unintelligible) based on the percentage of intelligible words in 10 pairs of phonetically balanced words. The percentage of intelligible words was obtained by the listeners' choice of test words from a list of phonemically similar words. Monsen (1981) found that for a hearing impaired speaker to be judged as highly intelligible, $90-100 \%$ of the words were chosen accurately. For a speaker to be judged at the next highest level of intelligibility, judges selected $80-89 \%$ of test words accurately. For a speaker to be judged as partially intelligible, $70-79 \%$ of test words were chosen correctly. Those speakers judged to be primarily unintelligible produced 60$69 \%$ of test words accurately, and speakers judged to be unintelligible produced $0-59 \%$ of test words accurately. A speaker who produced fewer than $60 \%$ of test words accurately was judged to be unintelligible. These results indicate that subjective categories of intelligibility actually span only a $60 \%$ $100 \%$ range.

\section{Formal Estimates of Intelligibility}

Formal methods of estimating a speaker's intelligibility include the multiple-choice format, determining the percentage of correct consonants rated according to frequency of occurrence, orthographic transcription, and completion tasks. To determine a speaker's intelligibility using a multiplechoice format, listeners are provided with a list of words consisting of the target 
word and at least one other phonetically similar word. As the words are uttered, the listener chooses the word from the list which best corresponds to what is heard.

Another method for measuring intelligibility is to determine which consonants are produced in error by a speaker, and calculating the impact on intelligibility based upon the frequency of occurrence in the language. For example, the Arizona Articulation Proficiency Scale (Fudala \& Reynolds, 1986) yields an intelligibility rating based on each consonant in error and the frequency of occurrence of each consonant.

To derive a percentage of intelligibility from an orthographic transcription of a speech sample, the number of words understood is divided by the number of words uttered in the sample. The resulting percentage serves as a percentage of intelligibility score (Yorkston \& Beukelman, 1978).

Another formal method of estimating intelligibility is to use a completion task. For this task, a listener hears a series of sentences and provides a word to complete the final sentence, from which one word has been deleted (Yorkston \& Beukelman, 1978).

Yorkston and Beukelman (1978) compared three formal measures of intelligibility: multiple choice, completion, and transcription. They found that the multiple choice format yielded the highest intelligibility percentages, the completion format yielded intermediate intelligibility percentages, and the transcription method yielded the lowest intelligibility percentages. Since intelligibility of speech is a product of the speaker, listener, and context (Kent et al., 1994), it follows that the method of assessing intelligibility that provides the least context to the listener produces the lowest scores. Therefore, this method may provide the most accurate measure of intelligibility. 
Summary

As children learn to speak their native language, they must establish and refine the fine motor movements required to produce recognizable phonemes. Once an approximation of several phonemes is achieved, the production of these phonemes is organized into patterns, or processes, which compose a phonological system. Phonological systems are comprised of numerous processes, each of which affects the production of entire classes of sounds (Hodson \& Paden, 1983).

Phonological processes used by individual speakers may be identified through the use of such assessment instruments as the BBTP (Bankson \& Bernthal, 1990), the KLPA (Khan \& Lewis, 1986), and the APP-R (Hodson, 1986). The identification of phonological processes forms an integral part of assessment of unintelligible speakers, in order to establish a course of intervention (Hodson \& Paden, 1983).

To determine the degree of intelligibility of a speaker, speech-language pathologists use both formal and informal measures. Formal measures of intelligibility include rating speakers according to a standard scale, multiple choice, completion, and orthographic transcription. Informal measures include a simple estimate of intelligibility in known and unknown contexts.

Among various factors affecting intelligibility, individual differences in phonologic systems have been shown to render some speakers more intelligible; others, less intelligible to a listener (Billman, 1986; Hodson, 1982; Hodson \& Paden 1983; Yavas \& Lamprecht, 1988); however, more studies that show a correlation between specific processes or combinations of processes and a speaker's degree of intelligibility are needed in order to form a hierarchy of treatment priorities for practicing speech-language pathologists. 


\section{CHAPTER III}

\section{METHOD}

The purpose of this study was to measure the correlation between the use of 10 phonological deviations as measured by percentage-of-occurrence scores obtained using the APP-R and the percentage of words intelligible from connected speech samples derived from orthographic transcriptions. The 10 phonological deviations measured included: 4 classes of omissions (i.e., omission of syllables, prevocalic singletons, postvocalic singletons, and consonant sequences) and 6 classes of deficiencies (i.e., stridents, velars, liquid $/ V$, liquid $/ r /$, nasals, and glides). Data used for this analysis were collected in a study previously conducted by Gordon-Brannan (1993).

\section{Participants}

Participants in the study included 4 judges and 46 speakers used in the Gordon-Brannan (1993) study. Judges

As part of an earlier study conducted by Gordon-Brannan (1993), four graduate students in the Speech and Hearing Sciences Program at Portland State University, including this investigator, were selected to listen to and transcribe connected speech samples. Criteria for selection included completed coursework in phonological disorders and clinical experience with clients who have phonological disorders.

\section{Speakers}

The speaker participants in the Gordon-Brannan (1993) study consisted of 46 children, aged 4:0 to 5:6. The speakers (from the greater Portland, Oregon metropolitan area) included 16 females and 30 males. Phonological 
skills of the speakers ranged from speakers without phonological deviations to speakers with multiple omissions and substitutions (see Appendix). The speakers were recruited from preschools and by referral from speech-language pathologists.

\section{Procedures}

Judging Tasks

Judges listened to taped continuous speech samples of the speakers a maximum of three times and transcribed the samples. A percentage of intelligibility score was generated by comparing the transcribed utterances to a transcription key made by Gordon-Brannan and the children's caregivers. Percentage of intelligibility scores of the continuous speech sample were obtained from the transcriptions by dividing the number of correctly understood words by the number of words uttered (Gordon-Brannan, 1993).

\section{Speaker Screening Procedures}

Speakers were selected after participating in a screening session held in a clinic room at Portland State University's Speech and Hearing Clinic. The screening session was designed to identify speakers with cognitive, motor, physical, or neurological disabilities that might have hindered their expressive speech abilities. Speakers with these disabilities were excluded from the study.

In order to identify potential physical, neuromotor, or cognitive deficits, a developmental history questionnaire was completed by the children's caregivers. Answers to the questions provided leads for discussion regarding the nature of such deficits; however, children with poor coordination, dyspraxia, or impairments that were no longer manifest were included in the study (Gordon-Brannan, 1993).

In order to assess receptive language ability, the Test of Auditory 
Comprehension of Language - Revised (TACL-R) (Carrow-Woolfolk, 1985) was administered. Speakers selected for participation in the study achieved a score above the 10th percentile, with one exception. In this case, the TACL-R score was not considered an accurate representation of the speaker's ability, based on informal interactions and on the referring clinician's report. Therefore, the speaker was included in the study (Gordon-Brannan, 1993).

To assess hearing ability, a pure-tone screening was administered at 20 $\mathrm{dB} \mathrm{HL}$ for the frequencies of $500,1000,2000$, and $4000 \mathrm{~Hz}$. Speakers selected for particiption in the study had bilateral thresholds at $35 \mathrm{~dB}$ or less at each of these frequencies, placing them in the range of normal hearing or mild hearing loss (Gordon-Brannan, 1993).

To ascertain that no deviation of resonance or laryngeal dysfunction would decrease speaker intelligibility, an informal conversation was held between the speaker and the investigator, during which the investigator listened for such vocal characteristics as hoarse voice and hypernasality (GordonBrannan, 1993).

\section{Speaker Tasks}

Speakers completed the APP-R (i.e., named 50 common objects) and conversed spontaneously with the examiner using visual stimuli to provide a 100-word continuous speech sample.

\section{Video and Audio Tape Recording}

To obtain video and audio recordings of each speaker's session, the investigator sat at a table with the speaker while the caregiver sat away from the table in the same room or outside the room. An AKG C451 capacitor flat microphone placed on a stand or on foam rubber was located 6 inches from the speaker's mouth. Volume input levels were controlled by a research assistant 
to create an audiotape using a Sharp SX D200 digital audio tape recorder. A videotape recording of the continuous speech sample was made concurrently by a research assistant using a Panasonic AG-100 VHS Reporter (GordonBrannan, 1993).

\section{Continuous Speech Sample Collection}

A continuous speech sample of 100 words was obtained from each speaker. The examiner posed several open-ended questions to begin the conversation, then elicited the language sample using five pictures and a picture book, The Relatives Came (Rylant \& Gammell, 1985). According to Gordon-Brannan (1993), the investigator's responses to speaker utterances were formulated so as not to provide contextual information that would increase the intelligibility of the speech samples. Utterances of both the examiner and speaker were recorded for the 100-word continuous speech sample. Echoic utterances, filler words, and interjections used by the speakers were not counted as part of the 100-word sample. For this study (Gordon-Brannan, 1993), filler words included words such as "oh," "no," "nope," "naw," "yes," "yeah," "yep," and "yup."

If the speaker produced more than 100 words while recounting a story based on the picture book, the 100 words for the sample were taken from this recounting. However, if the speaker said fewer than 100 words while recounting the story, the sample consisted of words uttered while viewing the five pictures in addition to the narrative sample (Gordon-Brannan, 1993).

To prepare the recordings for the judges, the digital recordings were placed in random order onto four digital and analog audio tapes for the judges. Duplicate recordings of five samples were included at the end of the speech sample listener tape for later investigation of intrajudge reliability. 
Scoring Keys

According to Gordon-Brannan (1993), orthographic transcriptions of all continuous speech samples were prepared by the examiner or by research assistants, then verified by the examiner, and lastly verified by the speakers' caregiver or parent by viewing the videotaped sample. The caregivers provided transcriptions of words that were unintelligible to the examiner and research assistants. The completed transcriptions were utilized as scoring keys to derive the percentage of intelligibility scores (Gordon-Brannan, 1993). Judges' Transcripts

As a group, judges were familiarized with the visual stimuli, (i.e., picture book and five pictures) before listening to the connected speech samples. Judges heard the samples at two separate times: first, in a group rating session, played on a Denon DTR-80P digital recorder with 2 Sony SRS-150 speakers for the purpose of rating the intelligibility samples and then individually at home on personal analog tape recorders (Gordon-Brannan, 1993). The judges were allowed to perform specific listening tasks at home to allow each person to complete the tasks at their own pace.

As stated in verbal and written instructions, judges were allowed to hear each sample a maximum of 3 times at home to complete the transcriptions. According to Gordon-Brannan, (1993), this limit served to approximate a first impression response as well as reduce the judges' dependence on short-term memory. Each utterance was transcribed orthographically, with " $X$ " symbolizing an unintelligible syllable. Samples were transcribed by hand or using a word processor.

Intelligibility Scores

To derive percentage of intelligibility scores for the connected speech 
samples, judges' transcriptions of speech samples were compared to scoring key transcriptions (described above). The percentage of intelligibility score for each sample consisted of the number of words correctly understood out of the 100-word sample by a judge. Thus, each speaker received four intelligibility percentages (Gordon-Brannan, 1993).

According to Gordon-Brannan (1993), words in the judges' transcriptions that differed significantly from those in the scoring keys were scored as incorrect, while words "that differed only in morphological form" (p. 51) were scored as correct. On five occasions, a word recorded as unintelligible on the scoring key was transcribed by a judge; the word was counted as correct in these five cases (Gordon-Brannan, 1993).

APP-R Administration and Scores

Individual speakers were administered the APP-R by the investigator according to APP-R administration guidelines. Errors were transcribed phonetically on the score sheet at the time of utterance, then input into the CAPD (Hodson, 1992) by a research assistant. These data were verified by a second research assistant, and finally by the original investigator (GordonBrannan, 1993).

\section{Data Analysis}

Percentage of occurrence scores for 10 categories of phonological processes obtained from the CAPD for all subjects included: (a) syllable omission; (b) consonant sequence reduction; (c) prevocalic singleton omission; (d) postvocalic singleton omission; (e) strident class deficiency; (f) velar obstruent deficiency; (g) liquid // deficiency; ( $h$ ) liquid /r/ deficiency; (i) nasal class deficiency; and (j) glide class deficiency. Percentage of intelligibility scores for the connected speech samples for all subjects could consist of a 
number between $0 \%$ and $100 \%$.

First, the relationship of each of the 10 processes with the percentage of intelligibility in connected speech was ascertained using the Pearson productmoment correlation (Pearson $\mathrm{r}$ ). Then, the effect of various combinations of phonological processes on intelligibility was explored using multiple regession analysis. Results from the analyses indicated which processes or combinations of processes significantly correlate with a speaker's degree of intelligibility. 


\section{CHAPTER IV \\ RESULTS AND DISCUSSION}

Results

The purpose of this study was to explore the relationship between the percentage of occurrence of 10 phonological deviations as measured by Hodson's (1986) Assessment of Phonological Processes - Revised (APP-R), singly and in combinations, and the degree of intelligibility of continuous speech of young children ages 4:0 to 5:6. Speech intelligibility was measured formally, being derived from orthographic transcription.

The following sections will address the results of the study. These sections will include descriptive data, results of a Pearson - $\mathbf{r}$ correlation of percentage-of-use of phonological processes scores from the APP-R with the percentage of intelligibility of a 100-word connected speech sample, and results from a stepwise multiple regression analysis of the percentage of use of combinations of phonological processes with mean intelligibility percentages of 100-word continuous speech samples.

Characteristics of the Sample

A summary of the sample used for this study including the age, gender, and mean percentage of intelligibility of each subject and percentages of occurrence for 10 phonological processes for each subject is outlined in the Appendix. The subjects ranged in age from 48 to 66 months, with a mean age of 55 months.

Descriptive Data

In Table 1, a summary of descriptive data is presented, including the means, standard deviations, and ranges of the percentage-of-occurrence 
scores for the 10 basic phonological processes measured by the APP-R. As indicated in the table, the phonological process with the highest mean percentage-of-occurrence score for all 46 subjects was liquid / $r /$ class deficiency at $62.5 \%$. The phonological process with the next highest mean percentage-ofuse was liquid /// class deficiency at $59.3 \%$. The phonological process with the lowest mean percentage-of-occurrence score was prevocalic singleton omission at $4.5 \%$. The mean percentage of intelligibility rating for the 100 -word continuous speech sample was $76 \%$ among all 46 subjects, with a standard deviation of 19 and a range of $42 \%$ to $99 \%$.

Correlation of Phonological Processes with Intelligibility of Connected Speech

The first research question posed was: Are specific phonological processes correlated with increased or decreased intelligibility in connected speech of children with varying levels of phonological proficiency as derived from orthographic transcription?

A Pearson I was utilized in order to explore the relationship of each of the 10 basic processes identified by the APP-R with the percentage of intelligibility in connected speech. As shown in Table 2, those single independent variables (i.e., percentage-of-use scores for 10 phonological processes) that had the strongest negative correlation with the dependent variable (i.e., mean percentage of intelligible words from 4 listeners' 
Table 1

Means. Standard Deviations, and Ranges for the 10 Phonological Processes for 46 Subjects

\begin{tabular}{lccc}
\hline Independent Variable & Mean (\%) & S.D. & Range (\%) \\
\hline \% of Intelligible Words & 76.00 & 18.80 & $19-99$ \\
Syllable Omission & 4.76 & 7.42 & $0-26$ \\
Prevocalic Singleton Omission & 4.52 & 6.82 & $0-25$ \\
Postrocalic Singleton Omission & 8.74 & 18.32 & $0-90$ \\
Consonant Sequence Omission & 29.37 & 33.19 & $0-100$ \\
Strident Class Deficiency & 23.87 & 32.55 & $0-100$ \\
Velar Class Deficiency & 28.46 & 35.67 & $0-100$ \\
Liquid N Class Deficiency & 59.33 & 39.61 & $0-100$ \\
Liquid /r/ Class Deficiency & 62.52 & 40.36 & $0-100$ \\
Nasal Class Deficiency & 6.43 & 14.17 & $0-89$ \\
Glide Class Deficiency & 20.00 & 24.86 & $0-90$ \\
\hline
\end{tabular}


Table 2

Correlation of Ten Phonological Processes with Mean Intelligibility Rating of 100-Word Continuous Speech Samples

Independent Variable Correlation with Dependent Variable

Consonant Sequence Omission $\quad-.84$

Glide Class Deficiency $\quad-.75$

Syllable Omission $\quad-.74$

Velar Class Deficiency $\quad-.74$

$\begin{array}{ll}\text { Postvocalic Singleton Omission } & -.72\end{array}$

$\begin{array}{ll}\text { Strident Class Deficiency } & -.71\end{array}$

Nasal Class Deficiency $\quad-.69$

Liquid // Class Deficiency $\quad-.56$

Prevocalic Singleton Omission $\quad-.55$

Liquid /r/ Class Deficiency $\quad-.49$ 
ratings of 46100 -word connected speech samples) included consonant sequence omission at -.84 , glide class deficiency at -.75 , and syllable omission/velar class deficiency at -.74 . Single phonological processes with the lowest negative correlation with the percentage of intelligible words included liquid $/ r /$ class deficiency at -.49 and prevocalic singleton omission at -.55 . Results indicate that occurrence of any single phonological process has a negative correlation with the mean intelligibility ratings of 100-word continuous speech samples. Significance is beyond the .001 level for all independent variables.

\section{Multiple Regression Analysis}

The second research question explored was: Are there specific phonological processes in combination that correlate with increased or decreased intelligibility in connected speech of children with varying levels of phonological proficiency?

Stepwise multiple regression analysis was used in order to determine the combination of phonological processes most strongly associated with decreased intelligibility. The forward stepwise procedure first selects the independent variable that has the largest partial correlation with the dependent variable, then continues to select independent variables meeting that criterion until R2 fails to increase by a significant amount (Horton, 1978), at the .05 level of significance.

Results from the analyses are summarized in Table 3. As shown in that table, the combined processes of consonant sequence omission, syllable omission, nasal class deficiency, and velar class deficiency accounted for $83 \%$ of the variance in the dependent variable. Occurrence of these processes was strongly correlated with decreased intelligibility of the connected speech 
Table 3

Multiple Correlation of Phonological Processes Scores with Mean Percentageof-Intelligibility Ratings of 100-Word Connected Speech Samples ( $N=46$ )

\begin{tabular}{|c|c|c|c|}
\hline Independent Variable(s) & Multiple $\underline{\mathrm{B}}$ & $\underline{\mathrm{B}}^{2}$ & $\begin{array}{c}\text { Adjusted } \\
\underline{\mathrm{B}}^{2}\end{array}$ \\
\hline $\begin{array}{l}\text { Consonant Sequence Omission } \\
\text { + Syllable Omission+ Nasal Class Deficiency } \\
\text { + Velar Class Deficiency }\end{array}$ & .91 & .83 & .81 \\
\hline $\begin{array}{l}\text { Consonant Sequence Omission } \\
+ \text { Syllable Omission+ Nasal Class Deficiency }\end{array}$ & .89 & .78 & .78 \\
\hline $\begin{array}{l}\text { Consonant Sequence Omission } \\
+ \text { Syllable Omission }\end{array}$ & .87 & .76 & .75 \\
\hline Consonant Sequence Omission & .84 & .70 & .69 \\
\hline
\end{tabular}


sample $\left(\underline{R}^{2}=.83\right)$. The combination of consonant sequence omission, syllable omission, and nasal class deficiency accounted for $78 \%$ of the variance of the dependent variable $\left(\underline{R}^{2}=.78\right)$. The combination of consonant sequence omission and syllable omission also showed a high correlation with decreased intelligibility; this combination of processes accounted for $76 \%$ of the variance of the dependent variable $\left(\underline{\mathrm{B}}^{2}=.76\right)$. Consonant sequence omission alone was found to account for $70 \%$ of the variance of the dependent variable $\left(\underline{R}^{2}=.70\right)$. For all measures, significance was beyond the .05 level.

Limitations of the Study

Inspection of the data reveals skewed distributions of independent and dependent variables. Since the distributions do not follow a normal curve, these correlations must be interpreted with great care. However, results of this study generally concur with findings previously reported.

Discussion

From 46 subjects in a sample of young speakers aged 4:0 - 5:6, the mean intelligibility rating of 100 -word connected speech samples was $76 \%$. The phonological process used by the 46 speakers most frequently was liquid $/ \mathrm{r} /$ class deficiency $(62.5 \%)$, followed by liquid $/ / /$ class deficiency $(59.3 \%)$. Since, according to Monsen (1981), an objective intelligibility rating of $75 \%$ corresponds to a subjective rating of partially intelligible, these results are in agreement with the findings of Hodson and Paden (1981) which state that intelligibility of speech is decreased by the use of these phonological processes.

Phonological processes that were used the least among the 46 subjects include prevocalic singleton omission, with a mean percentage-of-occurrence score of $4.5 \%$, and nasal class deficiency, with a mean percentage-of- 
occurrence score of $6.4 \%$. The relatively low occurrence of these phonological processes may be explained by the range in age of the subjects in this study, since Preisser et al. (1988) found that omission of prevocalic obstruents and nasal/glide deviation processes were used by subjects aged 1:6 to 1:9, but significantly decreased by the group aged 2:2 to 2:5. Given the age range of the 46 subjects in this study $(4: 0-5: 6)$, the majority of these subjects may have discontinued the use of those early developmental processes. Further, the results of this study indicate that speakers' use of these low incidence processes (i.e., nasal/glide deviation and omission of prevocalic obstruents) are related to decreased intelligibility. Although these processes occur infrequently, their occurrence is strongly associated with decreased intelligibility.

A further finding of this study that is not in accordance with Hodson (1983) is the lack of strident class omission/substitution processes in the multiple regression formula. Contrary to Hodson's (1983) findings, this process was not significantly linked with decreased intelligibility.

Other results revealed by this study are largely in agreement with results reported by Hodson and Paden $(1981 ; 1983)$, and Yavas and Lamprecht (1988); namely, that processes characterized by cluster reduction (i.e., consonant sequence omission) have a higher negative correlation with intelligibility than do processes characterized by substitution (i.e., class deficiencies). In addition, data revealed by this study indicate that the combination of phonological processes that correlate to the greatest degree with reduced intelligibility ratings are processes of omission (i.e., consonant sequence omission and syllable omission), rather than processes of substitution (i.e., class deficiency).

Other data revealed by this study show that nasal class deficiency, a 
process involving use of either substitution or omission processes in production of nasal consonants, was found to correlate highly with reduced intelligibility ratings in combination with consonant sequence omission and syllable omission. This presence of a substitution process as one of three variables hat correlate with low intelligibility of the spontaneous speech sample does not fully support the findings of Hodson and Paden (1981; 1983), that is, processes of omission are more strongly linked with decreased intelligibility than are processes of substitution.

In summary, occurrence of any measured phonological process was shown to have a negative correlation with intelligibility of connected speech. Similarly, combinations of phonological processes were shown to correlate with lowered speech intelligibility scores. Specifically, the use of consonant sequence omission alone was shown by both the Pearson - $\underline{r}$ and the stepwise multiple regression analysis to correlate negatively with intelligibility and to account for $70 \%$ of the variability of the mean intelligibility ratings. In addition, glide and velar class deficiencies showed strong negative correlation percentages with intelligibility (i.e., -.75 and -.74 , respectively). In terms of combinations of processes, the combination consisting of consonant sequence omission, syllable omission, nasal class deficiency, and velar class deficiency accounted for the highest percentage of variability of intelligibility (i.e., $83 \%$ ). The combination consisting of consonant sequence omission, syllable omission, and nasal class deficiency accounted for $78 \%$ of the variability, while use of consonant sequence omission and syllable omission accounted for $76 \%$ of the variability of the mean intelligibility ratings. The data suggest a hierarchy of combinations of phonological processes which negatively impact intelligibility. 


\section{CHAPTER V}

\section{SUMMARY}

The level of intelligibility of connected speech has been shown to be affected by many factors, including juncture, intensity of voice, pitch, rate, prosody, and phonological proficiency (Weiss, 1982). This study focused on systems of speech sound production and analyzed how the occurrence of 10 phonological processes, singly and in groups, corresponds with increased or decreased intelligibility of a connected speech sample.

Two research questions were posed for this study. The first question was: Are specific phonological processes correlated with increased or decreased intelligibility in connected speech of children with varying levels of phonological proficiency as derived from orthographic transcription? The second research question was: Do specific phonological processes in combination correlate with increased or decreased intelligibility in connected speech of children with varying levels of phonological proficiency?

In order to explore these questions, data from the Gordon-Brannan (1993) study were regrouped and analyzed. The data were generated by four judges and 46 speakers. Four judges, including this author, listened to and transcribed 100-word connected speech samples recorded by 46 young speakers aged 4:0 to $5: 6$. The percentage of intelligibility for each sample was derived by dividing the number of words understood in the sample by 100 . Each speech sample was thus given four intelligibility percentages, from which a mean intelligibility percentage was derived. The percentage-of-occurrence figures for 10 phonological processes (i.e., syllable omission, prevocalic singleton omission, postvocalic singleton omission, consonant sequence 
reduction, strident class deficiency, velar class deficiency, liquid /// class deficiency, liquid / $r$ / class deficiency, nasal class deficiency, and glide class deficiency) were obtained for each speaker by administration of the APP-R. Correlation of Phonological Processes with Intelligibility of Connected Speech

A Pearson product-moment correlation (Pearson $\underline{r}$ ) was utilized in order to explore the relationship of each of the 10 basic processes identified by the APP-R with the percentage of intelligibility in connected speech. The single independent variables (i.e., percentage-of-use scores for 10 phonological processes) with the strongest negative correlation with the dependent variable (i.e., mean percentage of intelligible words in the 100-word connected speech samples) included consonant sequence omission $(\underline{r}=-.84)$, glide class deficiency $(\underline{r}=-.75)$, and syllable omission/velar class deficiency $(\underline{r}=-.74)$. Single phonological processes with the lowest negative correlation with the percentage of intelligible words included liquid / $r /$ class deficiency $(r=-.49)$, and prevocalic singleton omission $(\underline{r}=-.55)$. Thus, each of the 10 single processes showed a significant negative correlation with the mean intelligibility ratings.

Consonant sequence omission was revealed to have the strongest negative correlation with intelligibility ratings. The remaining 9 processes were ranked in the following order, from strongest to weakest: glide class deficiency, syllable omission, velar class deficiency, postvocalic singleton omission, strident class deficiency, nasal class deficiency, liquid // class deficiency, prevocalic singleton omission, and liquid / $r$ / class deficiency. Results therefore indicate that the occurrence of any one of the 10 phonological processes has a negative correlation with the mean intelligibility rating of connected speech sample. 
Multiple Regression Analysis

Stepwise multiple regression analysis was used in order to determine the combination of phonological processes most strongly associated with decreased intelligibility. This forward stepwise procedure revealed that the combined processes of consonant sequence omission, syllable omission, nasal class deficiency, and velar class deficiency accounted for $83 \%$ of the variance in the dependent variable. Therefore, occurrence of these three processes was strongly correlated with decreased intelligibility of the connected speech sample $\left(\mathrm{R}^{2}=.83\right)$. The combination of consonant sequence omission, syllable omission, and nasal class deficiency accounted for $78 \%$ of the variance of the dependent variable $\left(\underline{R}^{2}=.78\right)$. The combination of consonant sequence omission and syllable omission also showed a high correlation with decreased intelligibility; this combination of processes accounted for $76 \%$ of the variance of the dependent variable $\left(\underline{R}^{2}=.76\right)$. Consonant sequence omission alone was found to account for $70 \%$ of the variance of the dependent variable $\left(\underline{R}^{2}=.70\right)$. For all measures, significance was at the .05 level.

Clinical Implications

The identification of single phonological processes, as well as combinations of phonological processes, that correlate significantly with decreased intelligibility suggests a hierarchy of treatment goals for clients with phonological disorders whose speech is characterized by the occurrence of various phonological processes. After an evaluation of a client's phonological system, the speech-language clinician can identify those processes that are highly correlated with decreased intelligibility ratings. Those processes can then be targeted as priority goals, contributing toward the primary goal of increasing the client's intelligibility of speech. 
Results from this study indicate that consonant sequence omission would be a priority remediation target. In addition, processes such as glide class deficiency, syllable omission, and velar class deficiency are high priority targets for clients with phonological disorders.

The combination of phonological processes shown to correlate most strongly with reduced intelligibility is comprised of consonant sequence omission, syllable omission, nasal class deficiency, and velar class deficiency. These results are in agreement with previous studies which indicate that the combined effects of more than one phonological process has a strong correlation with reduced intelligibility (Hodson \& Paden, 1981; Yavas \& Lamprecht, 1988). Therefore, a cycling approach to phonological intervention would be an effective method to decrease the use of combinations of phonological processes. In contrast to traditional articulation intervention methods, which focus on producing single phonemes correctly in varied phonetic contexts, the cycling approach targets phonological patterns. Multiple phonological processes can be targeted simultaneously, thereby increasing speech intelligibility (Hodson \& Paden, 1991).

Research Implications

During the process of completing this study, several research possibilities to further investigate the relationship between phonological process use and percentage of intelligibility have been revealed.

One possibility is to obtain phonetic transcriptions of 100-word continuous speech samples to identify phonological processes operating in a subject's connected speech. The percentage of occurrence of phonological processes in connected speech could then be correlated with the percentage of intelligibility of that speech sample. This method would compare two consistent 
measures rather than comparing measures of discrete, single-word productions with contextual productions in connected speech.

An additional possibility is to obtain a random sample of subjects and perform a correlational study of age, gender, and use of phonological processes of the sample. Such a study would add to the body of knowledge concerning the progression of phonological development and language acquisition cited in Chapter II.

Another possibility is to conduct a correlational study including various phonological processes in addition to those measured in this study (i.e., backing, "other"). Including more processes in the study would widen its scope; other processes may correlate significantly with decreased intelligibility. 
References

Bankson, N., \& Bernthal, J. (1990). Bankson-Bernthal test of phonology.

Chicago: Riverside Publishing Company.

Billman, K. (1986). Phonological processes and intelligibility of spontaneous utterances in young children. Unpublished master's thesis, San Diego State University, San Diego, CA.

Carrow-Woolfolk, E. (1985). Test of auditory comprehension of lanquage Revised. Allen, TX: DLM.

Churchill, J., Hodson, B., Jones, B., \& Novak, R. (1988). Phonological systems of speech-disordered clients. Language. Speech, and Hearing Services in Schools, 19, 100-106.

Dunn, C., \& Davis, B. (1983). Phonological process occurrence in phonologically disordered children. Applied Psycholinguistics, 4, 187-207. Dyson, A., \& Paden, E. (1983). Some phonological acquisition strategies used by two-year-olds. Journal of Childhood Communication Disorders, $7,6-18$.

Fudala, J. B., \& Reynolds, W. M. (1986). Arizona articulation proficiency scale (2nd Ed.). Los Angeles: Western Psychological Services.

Goldman, R., \& Fristoe, M. (1986). Goldman-Fristoe test of articulation. Circle Pines, MN: American Guidance Service.

Gordon-Brannan, M. (1993). Speech intelligibility assessment of young children with varying levels of phonological proficiency/deficiency. Unpublished doctoral dissertation, The Wichita State University, Wichita, KS. Grunwell, P. (1983). Clinical phonology. Rockville, MD: Aspen Systems Corp. Hodson, B. W. (1982). Remediation of speech patterns associated with low levels of phonological performance. In M. Crary (Ed.), Phonological intervention: Concepts and procedures. San Diego: College-Hill Press. 
Hodson, B. (1986). The assessment of phonological processes - Revised. Austin, TX: Pro-Ed.

Hodson, B. (1992). Computer analysis of phonological deviations. Stonington, IL: PhonoComp.

Hodson, B., \& Paden, E. (1981). Phonological processes which characterize unintelligible and intelligible speech in early childhood. Journal of Speech and Hearing Disorders, 46, 369-373.

Hodson, B., \& Paden, E. (1983). Targeting intelligible speech. San Diego: College-Hill.

Hodson, B., \& Paden, E. (1991). Targeting intelligible speech (2nd ed.). Austin, TX: Pro-Ed.

Horton, R. (1978). The General Linear Model. New York: McGraw-Hill. Ingram, D. (1976). Phonological disability in children. London: Arnold.

Kent, R., Miolo, G., \& Bloedel, S. (1994). The intelligibility of children's speech: A review of evaluation procedures. Manuscript submitted for publication. Khan, L., \& Lewis, N. (1986). Khan-Lewis phonological analysis. Circle Pines, MN: American Guidance Service.

Monsen, R. B. (1981). A usable test for the speech intelligibility of deaf talkers. American Annals of the Deaf, 126, 845-852.

Narusis, M. (1986). SPSS/PC+ for the IBM PC/XT/ATT. Chicago: SPSS Inc.

Oller, D. (1973). Regularities in abnormal child phonology. Journal of Speech and Hearing Disorders, $38,36-47$.

Preisser, D., Hodson, B., \& Paden, E. (1988). Developmental phonology: 18-29 months. Journal of Speech and Hearing Disorders. 53, 125-130.

Rylant, C., \& Gammell, S. (1985). The relatives came. New York: Bradbury Press. 
Schiavetti, N., Metz, D. E., \& Sitler, R. W. (1981). Construct validity of direct magnitude estimation and interval scaling of speech intelli-gibility: Evidence from a study of the hearing impaired. Journal of Speech and Hearing Research, 27, 623-626.

Shriberg, L., \& Kwiatkowski, J. (1982). Phonological disorders III: A procedure for assessing severity of involvement. Journal of Speech and Hearing Disorders, 47, 256-270.

Stampe, D. (1969). The acquisition of phonetic representation. Papers from the Fifth Regional Meeting of the Chicage Linguistic Society (pp. 443-454). Chicago: Chicago Linguistic Society.

Stoel-Gammon, C., \& Dunn, C. (1985). Normal and disordered phonology in children. Austin, TX: Pro-Ed.

Weiner, F. (1979). Phonological process analysis. Baltimore: University Park Press.

Weiss, C. (1982). Weiss intelligibility test. Tigard, OR: C.C. Publications.

Weiss, C. Gordon, M., \& Lillywhite, H. (1987). Clinical management of articulatory and phonologic disorders (2nd ed.). Baltimore: Williams \& Wilkins.

Yavas, M., \& Lamprecht, R. (1988). Processes and intelligibility in disordered phonology. Clinical Linquistics and Phonetics, 2, 329-345.

Yorkston, K. M., \& Beukelman, D. R. (1978). A comparison of techniques for measuring intelligibility of dysarthric speech. Journal of Communication Disorders, 11, 499-512. 


\section{Appendix}

Characteristics of Speakers

\begin{tabular}{|c|c|c|c|c|c|c|c|c|c|c|c|c|c|}
\hline Subject & Gender & $\mathrm{Age}^{*}$ & $\%$ Intell. & 1 & 2 & 3 & 4 & 5 & 6 & 7 & 8 & 9 & 10 \\
\hline 1 & $M$ & 56 & 69 & 5 & 2 & 0 & 35 & 56 & 64 & 73 & 76 & 0 & 40 \\
\hline 2 & $M$ & 50 & 36 & 11 & 18 & 32 & 78 & 81 & 45 & 73 & 100 & 16 & 40 \\
\hline 3 & $M$ & 65 & 93 & 0 & 0 & 0 & 0 & 0 & 0 & 9 & 86 & 0 & 0 \\
\hline 4 & $F$ & 66 & 86 & 0 & 0 & 0 & 5 & 2 & 0 & 18 & 81 & 5 & 10 \\
\hline 5 & $M$ & 48 & 42 & 26 & 7 & 19 & 85 & 84 & 45 & 100 & 100 & 16 & 50 \\
\hline 6 & $M$ & 60 & 80 & 5 & 2 & 13 & 43 & 93 & 9 & 82 & 95 & 5 & 10 \\
\hline 7 & $M$ & 57 & 50 & 16 & 7 & 26 & 45 & 47 & 41 & 91 & 57 & 26 & 20 \\
\hline 8 & $F$ & 61 & 70 & 0 & 5 & 23 & 83 & 63 & 27 & 91 & 100 & 16 & 30 \\
\hline
\end{tabular}

*Age in months

KEY: 1 - Syllable Omission; 2 - Prevocalic Singleton Omission; 3 - Postvocalic Singleton Omission; 4 - Consonant Sequence Omission; 5 - Strident Class Deficiency; 6 - Velar Class Deficiency; 7 - Liquid /// class Deficiency; 8 - Liquid /r/ Class Deficiency; 9 - Nasal Class Deficiency; 10 - Glide Class Deficiency. 


\section{Appendix}

Characteristics of Speakers (continued)

\begin{tabular}{|c|c|c|c|c|c|c|c|c|c|c|c|c|c|}
\hline Subject & Gender & Age $^{*}$ & $\%$ Intell. & 1 & 2 & 3 & 4 & 5 & 6 & 7 & 8 & 9 & 10 \\
\hline 9 & $\mathrm{~F}$ & 60 & 83 & 5 & 0 & 0 & 3 & 0 & 0 & 36 & 33 & 0 & 0 \\
\hline 10 & $M$ & 51 & 71 & 0 & 2 & 0 & 40 & 12 & 27 & 100 & 100 & 0 & 20 \\
\hline 11 & $F$ & 54 & 88 & 5 & 0 & 0 & 3 & 0 & 0 & 55 & 0 & 0 & 0 \\
\hline 12 & $M$ & 56 & 73 & 5 & 0 & 0 & 0 & 2 & 0 & 73 & 43 & 0 & 0 \\
\hline 13 & $M$ & 60 & 79 & 0 & 7 & 0 & 43 & 28 & 27 & 91 & 95 & 16 & 50 \\
\hline 14 & $M$ & 60 & 85 & 0 & 2 & 0 & 8 & 5 & 5 & 100 & 100 & 0 & 20 \\
\hline 15 & $M$ & 53 & 61 & 5 & 2 & 3 & 78 & 72 & 100 & 82 & 86 & 11 & 50 \\
\hline 16 & $M$ & 54 & 89 & 0 & 0 & 0 & 3 & 0 & 50 & 0 & 76 & 0 & 10 \\
\hline
\end{tabular}

${ }^{*}$ Age in months

KEY: 1 - Syllable Omission; 2 - Prevocalic Singleton Omission; 3 - Postvocalic Singleton Omission; 4 - Consonant Sequence Omission; 5 - Strident Class Deficiency; 6 - Velar Class Deficiency; 7 - Liquid /// class Deficiency; 8 - Liquid / $/ \mathrm{I}$ Class Deficiency; 9 - Nasal Class Deficiency; 10 - Glide Class Deficiency. 


\section{Appendix}

Speaker Characteristics (continued)

\begin{tabular}{|c|c|c|c|c|c|c|c|c|c|c|c|c|c|}
\hline Subject & Gender & Age $^{*}$ & $\%$ intell. & 1 & 2 & 3 & 4 & 5 & 6 & 7 & 8 & 9 & 10 \\
\hline 17 & $M$ & 56 & 64 & 0 & 25 & 52 & 53 & 98 & 100 & 91 & 100 & 0 & 0 \\
\hline 18 & $F$ & 62 & 98 & 0 & 0 & 0 & 0 & 0 & 0 & 100 & 86 & 0 & 0 \\
\hline 19 & $M$ & 65 & 94 & 0 & 5 & 0 & 8 & 0 & 5 & 100 & 86 & 0 & 20 \\
\hline 20 & $F$ & 48 & 90 & 0 & 0 & 3 & 0 & 0 & 0 & 27 & 0 & 5 & 0 \\
\hline 21 & $F$ & 62 & 50 & 26 & 11 & 10 & 93 & 26 & 64 & 91 & 62 & 11 & 70 \\
\hline 22 & $M$ & 56 & 86 & 0 & 2 & 0 & 15 & 33 & 14 & 82 & 38 & 0 & 10 \\
\hline 23 & $M$ & 60 & 86 & 5 & 0 & 3 & 30 & 9 & 0 & 64 & 100 & 5 & 30 \\
\hline 24 & $F$ & 50 & 67 & 21 & 20 & 58 & 68 & 72 & 41 & 100 & 95 & 21 & 20 \\
\hline
\end{tabular}

*Age in months

KEY: 1 - Syllable Omission; 2 - Prevocalic Singleton Omission; 3 - Postvocalic Singleton Omission; 4 - Consonant Sequence Omission; 5 - Strident Class Deficiency; 6 - Velar Class Deficiency; 7 - Liquid /// class Deficiency; 8 - Liquid /r/ Class Deficiency; 9 - Nasal Class Deficiency; 10 - Glide Class Deficiency. 


\section{Appendix}

Characteristics of Speakers (continued)

\begin{tabular}{|c|c|c|c|c|c|c|c|c|c|c|c|c|c|}
\hline Subject & Gender & Age $^{*}$ & $\%$ Intelligible & 1 & 2 & 3 & 4 & 5 & 6 & 7 & 8 & 9 & 10 \\
\hline 25 & M & 53 & 19 & 16 & 9 & 90 & 100 & 100 & 100 & 91 & 100 & 89 & 70 \\
\hline 26 & $\mathrm{~F}$ & 59 & 92 & 11 & 2 & 0 & 0 & 5 & 0 & 18 & 10 & 0 & 0 \\
\hline 27 & $M$ & 50 & 92 & 0 & 0 & 0 & 3 & 0 & 0 & 9 & 10 & 0 & 0 \\
\hline 28 & $M$ & 50 & 90 & 0 & 2 & 0 & 5 & 2 & 9 & 18 & 5 & 0 & 10 \\
\hline 29 & $M$ & 60 & 95 & 0 & 0 & 0 & 0 & 0 & 5 & 0 & 24 & 0 & 0 \\
\hline 30 & $F$ & 58 & 94 & 0 & 0 & 0 & 0 & 0 & 0 & 0 & 0 & 0 & 0 \\
\hline 31 & $F$ & 53 & 96 & 0 & 0 & 0 & 3 & 0 & 0 & 0 & 0 & 0 & 0 \\
\hline 32 & M & 51 & 96 & 0 & 0 & 0 & 0 & 0 & 0 & 9 & 0 & 0 & 0 \\
\hline
\end{tabular}

${ }^{*}$ Age in months

KEY: 1 - Syllable Omission; 2 - Prevocalic Singleton Omission; 3 - Postvocalic Singleton Omission; 4 - Consonant Sequence Omission; 5 - Strident Class Deficiency; 6 - Velar Class Deficiency; 7 - Liquid /// class Deficiency; 8 - Liquid /r/ Class Deficiency; 9 - Nasal Class Deficiency; 10 - Glide Class Deficiency. 


\section{Appendix}

Characteristics of Speakers (continued)

\begin{tabular}{|c|c|c|c|c|c|c|c|c|c|c|c|c|c|}
\hline Subject & Gender & Age $^{*}$ & $\%$ Intelligible & 1 & 2 & 3 & 4 & 5 & 6 & 7 & 8 & 9 & 10 \\
\hline 33 & M & 55 & 76 & 5 & 0 & 0 & 8 & 0 & 100 & 9 & 100 & 0 & 10 \\
\hline 34 & M & 48 & 81 & 0 & 5 & 0 & 3 & 5 & 0 & 82 & 100 & 0 & 10 \\
\hline 35 & M & 48 & 46 & 21 & 7 & 19 & 65 & 12 & 86 & 64 & 100 & 11 & 60 \\
\hline 36 & M & 49 & 86 & 0 & 5 & 0 & 28 & 12 & 18 & 100 & 100 & 11 & 10 \\
\hline 37 & $F$ & 58 & 99 & 0 & 0 & 0 & 0 & 0 & 0 & 0 & 0 & 0 & 0 \\
\hline 38 & $F$ & 55 & 91 & 0 & 0 & 0 & 5 & 0 & 0 & 0 & 14 & 0 & 0 \\
\hline 39 & M & 57 & 71 & 0 & 2 & 0 & 48 & 9 & 32 & 91 & 86 & 11 & 20 \\
\hline 40 & $F$ & 49 & 56 & 5 & 14 & 13 & 70 & 19 & 100 & 100 & 57 & 11 & 80 \\
\hline
\end{tabular}

*Age in months

KEY: 1 - Syllable Omission; 2 - Prevocalic Singleton Omission; 3 - Postvocalic Singleton Omission; 4 - Consonant Sequence Omission; 5 - Strident Class Deficiency; 6 - Velar Class Deficiency; 7 - Liquid /// class Deficiency; 8 - Liquid / $/ \mathrm{r}$ Class Deficiency; 9 - Nasal Class Deficiency; 10 - Glide Class Deficiency. 


\section{Appendix}

Characteristics of Speakers (continued)

\begin{tabular}{|c|c|c|c|c|c|c|c|c|c|c|c|c|c|}
\hline Subject & Gender & $\mathrm{Age}^{*}$ & $\%$ Intell. & 1 & 2 & 3 & 4 & 5 & 6 & 7 & 8 & 9 & 10 \\
\hline 41 & $M$ & 56 & 98 & 0 & 0 & 0 & 0 & 0 & 0 & 0 & 0 & 0 & o \\
\hline 42 & $M$ & 54 & 71 & 0 & 0 & 0 & 8 & 12 & 18 & 18 & 0 & 0 & ) \\
\hline 43 & $F$ & 58 & 78 & 5 & 2 & 0 & 8 & 2 & 0 & 91 & 90 & 0 & 0 \\
\hline 44 & $F$ & 48 & 86 & 0 & 0 & 0 & 8 & 7 & 9 & 18 & 90 & 0 & 10 \\
\hline 45 & $M$ & 49 & 86 & 5 & 25 & 6 & 80 & 58 & 68 & 100 & 100 & 5 & \\
\hline 46 & $M$ & 57 & 47 & 16 & 18 & 29 & 90 & 72 & 100 & 100 & 95 & 5 & \\
\hline
\end{tabular}

*Age in months

KEY: 1 - Syllable Omission; 2 - Prevocalic Singleton Omission; 3 - Postvocalic Singleton Omission; 4 - Consonant Sequence Omission; 5 - Strident Class Deficiency; 6 - Velar Class Deficiency; 7 - Liquid /// class Deficiency; 8 - Liquid / $r /$ Class Deficiency; 9 - Nasal Class Deficiency; 10 - Glide Class Deficiency. 